\title{
New implementations of Single-Stage Power-Factor-Correctors with Voltage- Doubler Line Rectifier
}

\author{
J. Sebastián*, A. Fernández*, M. M. Hernando*, J. A.Villarejo**, and M. Rascón*** \\ *Universidad de Oviedo. Departamento de Ingeniería Eléctrica, Electrónica, de Computadores y Sistemas. \\ Grupo de Electrónica Industrial. \\ Campus Universitario de Viesques. 33204 Gijón. SPAIN \\ Phone: +349851820 85. Fax: +34 9851821 38. E-Mail: sebas@ate.uniovi.es \\ ** Universidad Politécnica de Cartagena. Departamento de Tecnología Electrónica. \\ Campus Muralla del Mar. 30202 Cartagena. SPAIN \\ ***ALCATEL. Technology Group.
}

Av. Princesa Juana de Austria, Km 8,7. 28021 Madrid, SPAIN

\begin{abstract}
This paper deals with a new implementation of a Voltage-Doubler Single-Stage Power Factor Corrector (VD$S^{2} P F C$ ). This new VD-S ${ }^{2} P F C$ provides a reduction (by half) of the total voltage drop due to diodes conducting at the same time from the line input to the energy-storage capacitors. Moreover, the size of the additional inductors used to shape the line current is dramatically reduced due to the fact that these inductors form part of an additional output of the main dc-to-dc converter, which is based on a full-wave rectifier and, therefore, these inductors are operating at twice the converter switching frequency and with a higher duty cycle than in the case of being based on a half-wave rectifier, as in some previous cases. The experimental results show that both inductors can be built into two E20 cores for a $100 \mathrm{~W}, 62 \mathrm{~V}_{\mathrm{d}}$ prototype. The voltage across the series connection of both energy-storage capacitors is lower than $500 \mathrm{~V}$ and the total efficiency of this prototype is $\mathbf{9 2 - 9 0 \%}$.
\end{abstract}

\section{INTRODUCTION}

Many Single-Stage Power Factor Correctors (S ${ }^{2}$ PFCs) [1-8] (see Fig.1) have been recently proposed to achieve both the standard dynamic behaviour of conventional dcto-dc converters and the desired compliance with the regulations (especially with the IEC-1000-3-2). When the ac input voltage changes in a moderate range (for example in either the American or the European range), $S^{2} P F C s$ are very attractive, because they combine fast output voltage regulation and moderate input current harmonic content. It should be noted that both characteristics are achieved in $S^{2} P F C s$ maintaining the cost and the complexity of the circuit relatively low. However, if standard $S^{2}$ PFCs are designed to operate in universal-line applications (85-265 Vac), they become less attractive due to variations of the voltage across the energy-storage capacitor with load and, especially, with input voltage. These variations cause two negative effects:

- A detrimental effect on the conversion efficiency [9], because the voltage across the energy-storage capacitor is also the input voltage of the dc-to-dc converter part of the $S^{2} \mathrm{PFC}$.

- A relatively large size of the energy-storage capacitor [9] because its capacitance must be high enough to meet the hold-up time requirements at low voltage $(110 \mathrm{Vac})$ and its voltage rating must be around $450 \mathrm{Vdc}$
These drawbacks can be partially overcome by modifying some $\mathrm{S}^{2} \mathrm{PFC}$ topologies to use a line rectifier that can operate as a conventional line rectifier in the European range and as a voltage-doubler line rectifier in the American range. This option was presented in $[10,11]$ applied to the topologies studied in [3-5]. Other very attractive implementations of Voltage-Doubler SingleStage Power factor Correctors (VD-S ${ }^{2}$ PFCs) have been presented in [12] (see Fig. 2a and 2b). In this paper, a new implementation of VD-S ${ }^{2}$ PFC is going to be presented (see Fig. 2c). This new VD-S²PFC has the following advantages over the previous ones:

- Only two diodes (instead of four in [10-12]) are
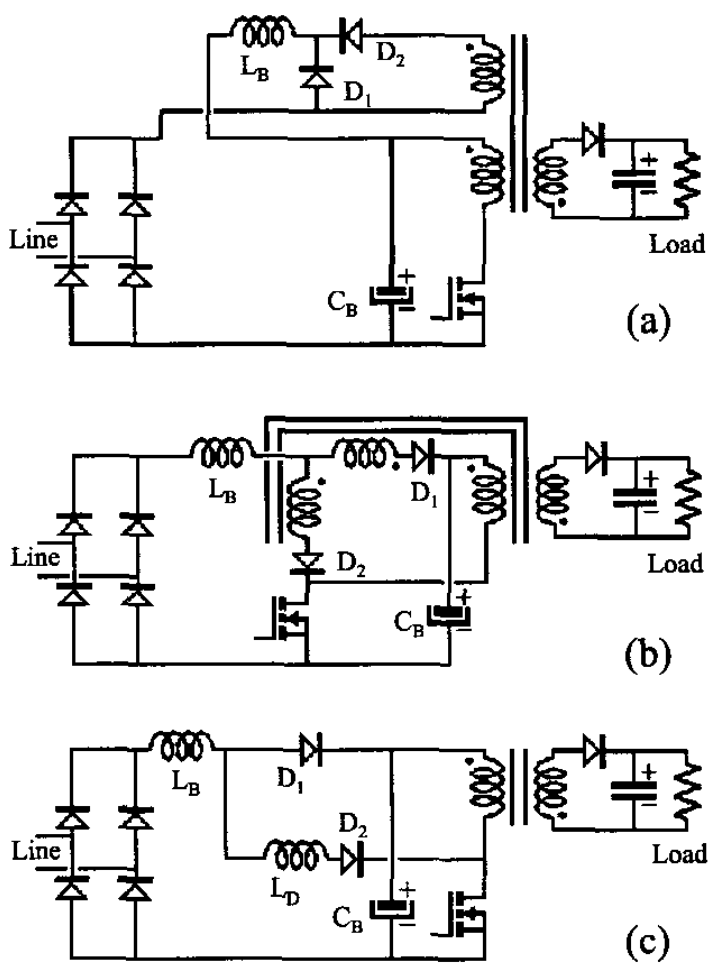

Fig. 1. Several examples of $S^{2}$ PFCs based on a Flyback dc-to-dc converter: a) implementation presented in [1]; b) implementation presented in $[3,4]$; c) implementation presented in $[5,6]$. 


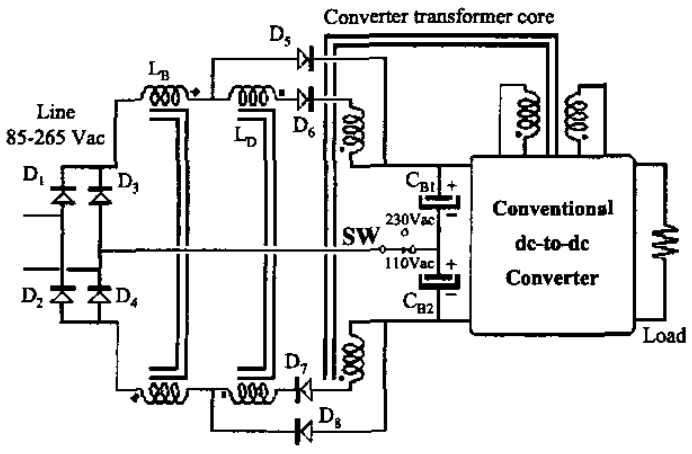

a)

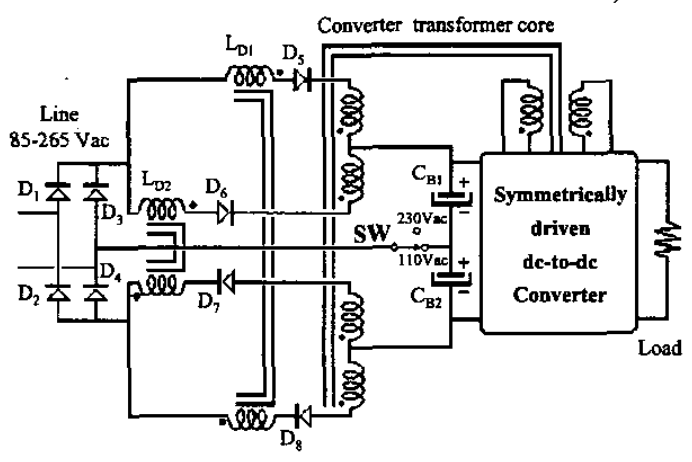

(b)

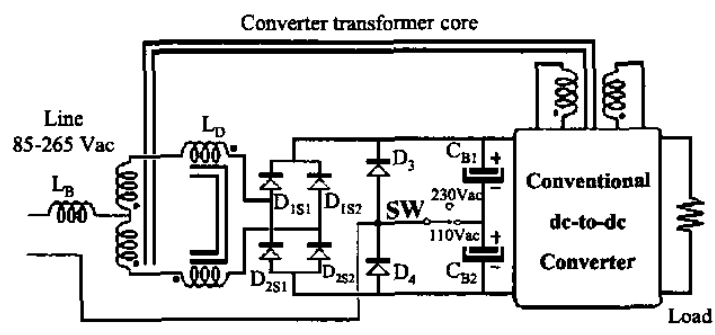

(c)

Fig. 2. Several VD-S'PFCs: a) implementation presented in [11]; b) implementation presented in [12]; c) implementation presented in this paper.

connected in series between the line input and the energy-storage capacitors. In the previous VD-S ${ }^{2} P F C s$, two diodes are conducting together in the American range (SW closed) and four are conducting together in the European range (SW open). These numbers are divided by two in the proposed topology.

- All the additional inductors added to shape the line current operate at twice the switching frequency. This occurs not only with symmetrically-driven topologies (such as half-bridge, full-bridge and push-pull) but also with some asymmetrically-driven topologies (such as flyback, SEPIC and Cuk). As a result of the higher switching frequency operation, the total size of the additional inductors is very small, even if the boost inductor $\mathrm{L}_{\mathrm{B}}$ has been designed to operate in Continuous Conduction Mode (CCM).

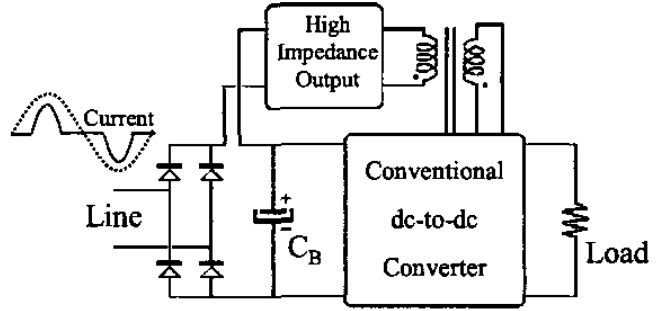

(a)

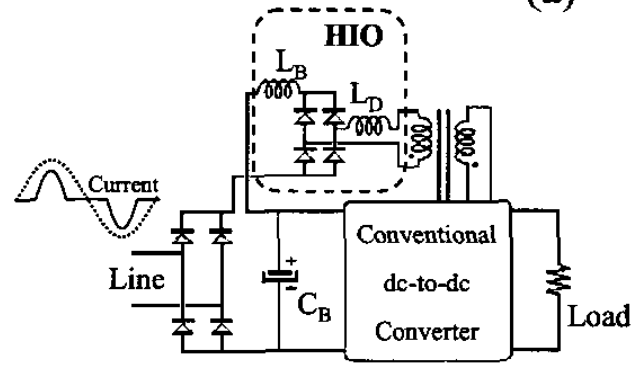

(b)

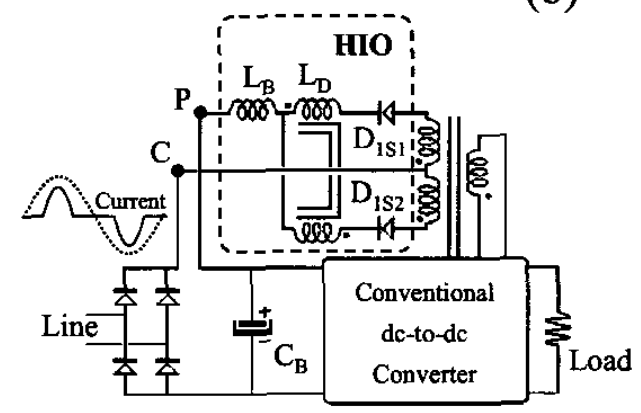

(c)

Fig. 3. a) General scheme for many $S^{2} P F C s ; b$ ) implementation presented in $[7,8]$ for the European range; c) implementation presented in $[7,8]$ for the American range.

\section{MODIFYING SINGLE-STAGE POWER-FACTOR- CORRECTORS TO IMPROVE THEIR EFFICIENCY AT LOW LINE VOLTAGE BY INTEGRATING HIGH-FREQUENCY AND LINE- RECTIFIER DIODES}

Several types of $S^{2}$ PFCs are based on the connection of an additional "High-Impedance Output" (HIO) between the input rectifier and the energy-storage bulk capacitor $C_{B}$ (see Fig. 3a). This HIO can be implemented in several different ways. Two attractive implementations are shown in Fig. 3b-c, [7-8]. The total size of the additional inductors $L_{B}$ and $L_{D}$ is slightly lower in the first implementation (Fig. $3 \mathrm{~b}$ ), but two high-frequency diodes and two line-rectifier diodes are connected in series between the input line and the energy-storage bulk capacitor $C_{B}$. On the other hand, the two high-frequency diodes are reduced to only one in the second implementation (Fig. 3c). Therefore, the former is more attractive for the European range of input voltage (where the voltage drop across the diodes is less 

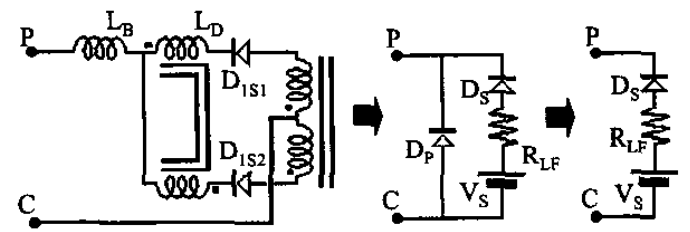

Fig. 4. Process to obtain the equivalent circuit of the HIOs shown in Fig. 3b $\sim$.

significant), whereas the latter is more attractive for the American and Japanese range.

However, the number of diodes conducting simultaneously can be reduced again by integrating the HIO high-frequency diodes and the line-rectifier lowfrequency diodes. Figure 4 shows the equivalent circuit for the HIOs shown in Fig. 3b-c. This equivalent circuit consist of a voltage source $V_{S}$, a loss-free resistor $R_{L F}[6-8]$ and two diodes, a series diode $D_{S}$ and a parallel diode $D_{P}$. The function of $D_{S}$ in this equivalent circuit is to represent the fact that the current can only flow from the positive terminal $\mathbf{P}$ to the common terminal $\mathrm{C}$ (as in any additional converter output with diodes), whereas the function of $D_{P}$ is to represent the fact that the output voltage cannot reverse (the same as in any additional converter output with diodes). A proper design of the HIO according to [6-8] results in $D_{\mathrm{P}}$ always being reverse biased and, therefore, it cannot be used for integration purposes. Therefore, the final equivalent circuit to start the integration process will be the one shown in Fig. 4c. Figure 5a shows the general scheme given in Fig. 3a with this equivalent circuit. As can be easily deduced from this figure, there is current passing through $R_{L F}$ and $V_{S}$ either when the couple of diodes $D_{R 1}-$ $\mathrm{D}_{\mathrm{R} 4}$ or the couple of diodes $\mathrm{D}_{\mathrm{R} 3}-\mathrm{D}_{\mathrm{R} 2}$ are conducting. This means that the integration process of $D_{S}$ as one of the diodes of the couples $D_{R 1}-D_{R 4}$ or $D_{R 3}-D_{R 2}$ will imply the duplication of $R_{L F}$ and $V_{S}$.

Figure $5 \mathrm{~b}$ shows one of the possible integrated options. Two sets of elements $R_{L F}, V_{S}$ and $D_{S}$ have been used to eliminate the rectifier diodes $D_{R 1}$ and $D_{R 2}$. Now, only two

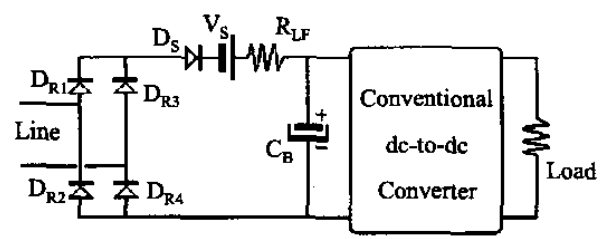

(a)

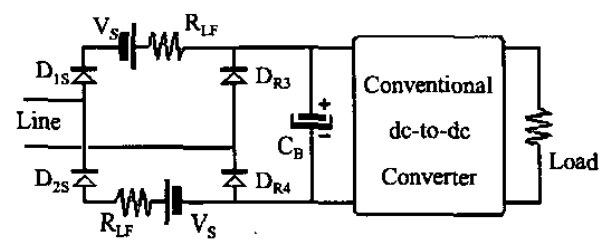

(b)

Fig. 5. a) Equivalent circuit for converters with the HIOs shown in Fig. 3b-c. b) Equivalent circuit after integrating high-frequency and linerectifier diodes.

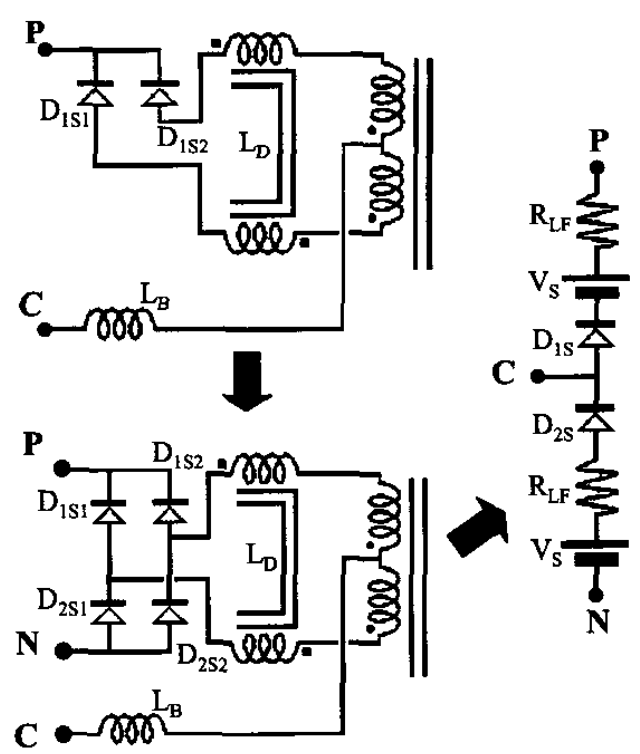

Fig. 6. Process to obtain two sets of elements $D_{S}, V_{S}$ and $R_{L F}$ from a HIO.

diodes (the couple $D_{1 S}-D_{R 4}$ or the couple $D_{R 3}-D_{2 S}$ ) are conducting at the same time, whereas three diodes (either $D_{R 1}-D_{S}-D_{R 4}$ or $D_{R 3}-D_{S}-D_{R 4}$ ) were conducting at the same time with the previous circuit (Fig. 5a).

The implementation of the new rectifier leg with two sets of elements $R_{L F}, V_{S}$ and $D_{S}$ can be obtained by duplicating all the elements of a HIO. However, a more attractive option is to avoid the duplication of the HIO magnetic elements. Figure 6 shows the steps to do this:

- The first step is to move $L_{B}$ from the positive terminal $P$ to the common terminal C.

- The second step is to obtain not only a positive output, but also a negative one. Diodes $\mathrm{D}_{1 \mathrm{S1}}$ and $\mathrm{D}_{1 \mathrm{~S} 2}$ in Fig. $6 a-b$ are in charge of generating the positive output, whereas diodes $D_{2 S 1}$ and $D_{2 S 2}$ are in charge of generating the negative one. When the current flows from terminal $P$ to terminal $C$, either $D_{1 S 1}$ or $D_{1 S 2}$ (depending on the voltage across the transformer) are conducting, whereas neither $D_{2 S 1}$ and $D_{2 S 2}$ are conducting. The situation is just the opposite when the current flows from terminal $\mathrm{C}$ to terminal $\mathrm{N}$ (either $\mathrm{D}_{2 \mathrm{~S} 1}$ or $\mathrm{D}_{2 \mathrm{~S} 2}$ are conducting, whereas both $\mathrm{D}_{1 \mathrm{~S} 1}$ and $\mathrm{D}_{1 \mathrm{~S} 2}$ are not conducting). Therefore, the elements of the HIO (that is, inductors $L_{B}$ and $L_{D}$ and the additional transformer winding) are alternatively connected between terminals $P$ and $C$ (when the current flows from $\mathrm{P}$ to $\mathrm{C}$ ) and between terminals $\mathrm{N}$ and $\mathrm{C}$ (when the current flows from $\mathrm{C}$ to $\mathrm{N}$ ). Therefore, the equivalent elements $R_{L F}$ and $V_{S}$ alternatively can be seen to be connected between either terminals $\mathrm{P}$ and $\mathrm{C}$ or terminals $\mathrm{N}$ and $\mathrm{C}$. This is just the effect desired. The equivalent circuit is the one shown in Fig. 6c.

- The third step in the integration process is to substitute the two sets of equivalent elements $R_{L . F}, V_{S}$ 


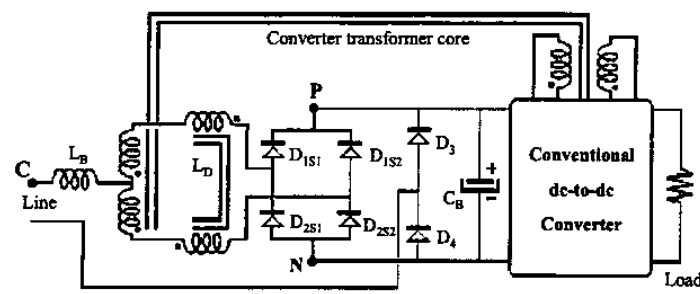

Fig. 7. New version of the converter shown in Fig. $3 \mathrm{c}$ after integrating high-frequency and line-rectifier diodes.

and $D_{S}$ in Fig. $5 b$ for the real elements shown in Fig. 6b. The final implementation is given in Fig. 7. From this figure, it can be deduced that only one highfrequency diode and one line-rectifier diode are conducting at the same time. Thus, in the positive halfcycle of the line voltage, either $\mathrm{D}_{1 \mathrm{~S} 1}$ or $\mathrm{D}_{1 \mathrm{~S} 2}$ (depending on the voltage across the converter transformer) and $\mathrm{D}_{4}$ are conducting. The same occurs in the negative halfcycle, but for either $D_{2 S 1}$ or $D_{2 S_{2}}$ and $D_{3}$.

The procedure to design the tums ratio of the additional transformer winding and inductors $L_{D}$ and $L_{B}$ is exactly the same as shown in [6-8]. However, the high-frequency diodes $D_{1 \mathrm{~S} 1}, D_{1 \mathrm{~S} 2}, \mathrm{D}_{2 \mathrm{~S} 1}$ and $\mathrm{D}_{2 \mathrm{~S} 2}$ must be rated to withstand the input voltage of the dc-to-dc converter, which is in practice a higher voltage than the voltage withstood by the high-frequency diodes $D_{1 s 1}$ and $D_{1 S 2}$ in Fig. $3 b$.

Having only the voltage drop corresponding to two diodes instead of three improves the converter efficiency. This improvement is more significant for converters designed to operate only from the American and Japanese lines than for converters designed to operate only from the European line. However, this improvement is not the main advantage of the converter shown in Fig. 7, but rather its adaptability to operate with a line voltage-doubler at the input.

\section{A NEW TOPOLOGY OF VOLTAGE-DOUBLER SINGLE- STAGE POWER-FACTOR-CORRECTOR}

The circuit shown in Fig. 7 can be easily adapted to be used with a voltage-doubler (see Fig. $2 \mathrm{c}$ ). The operation of the line rectifier is as follows:

When the range switch SW is in the "110Vac" position, $D_{3}$ and $D_{4}$ never conduct because they are reverse biased by $C_{B 1}$ and $C_{B 2}$. The bulk capacitor $C_{B 1}$ is charged during the positive interval of the line voltage through one of the diodes $D_{1 s}$ (either $D_{1 s 1}$ or $D_{1 s 2}$ ), the additional inductors and the additional transformer winding. The same occurs for $\mathrm{C}_{\mathrm{B} 2}$ during the negative interval, but the diode involved in the process is either $D_{2 s 1}$ or $D_{2 s 2}$. Due to circuit symmetry, both capacitors are identically charged. The voltage across the input of the dc-to-dc converter will be twice as large as the voltage across one bulk capacitor. Finally, it should be noted that only one diode voltage drop is placed between the line input and the energystorage bulk capacitors at the same time.

When SW is in the "230Vac" position, both bulk capacitors are charged together. The diodes involved in the conduction process are $\mathrm{D}_{4}$ (during the positive halfcycle) and $D_{3}$ (during the negative one). In this case, two diodes (one high-frequency diode and one linerectifier diode) are conducting at the same time.

The design procedure of inductors $L_{B}$ and $L_{D}$ and of the turns ratio of the additional winding is the same as the one presented in references [6-8]. However, the effect of the voltage doubler must be taken into account only to calculate those dc-to-dc converter parameters that must be calculated at minimum line voltage (e.g. maximum converter duty cycle, transformer turns ratio, etc) and to compute the evolution of the voltage across the input port of the dc-to-dc converter properly.

The design procedure presented in references [6-8] assumes that the inductance of $L_{B}$ is several times (3-5) as high as the inductance of $L_{D}$. However, the inductance of $L_{B}$ can be chosen lower than the values proposed in these references, according to the design procedure shown in [13]. Thus, choosing $\mathrm{L}_{\mathrm{B}}$ approximately equal to $\mathrm{L}_{\mathrm{D}} / 4$, a good trade-off between input current ripple and inductor size can be established. Moreover, it should be noted that both inductors form part of an additional output (the HIO) based on a full-wave rectifier, which means that the magnetic elements used to modulate its output voltage according to the line current (that is, $\mathrm{L}_{\mathrm{D}}$ ) and the filter inductor $L_{B}$ will be lower than in the case of using a halfwave rectifier $[10,11]$. In other words, the $\mathrm{HIO}$ is operating at twice the converter switching frequency and the HIO duty cycle is higher than in the case of previous $\mathrm{HIO}$ based on a half-wave rectifier. Due to these facts, the final size of these inductors is quite small (for example, two E20 cores can be used to implement them for a $100 \mathrm{~W}$ converter).

\section{EXPERDMENTAL RESULTS}

A prototype of the converter proposed (see Fig. 8) has been built and tested. As this figure shows, the "Conventional dc-to-dc Converter" in Fig. $2 c$ is a halfbridge converter in this prototype. The input line voltage can be either the American range $(85-130 \mathrm{~V})$ or the European one (190-265 V), depending on the position of the mechanical range switch SW. The output is $62 \mathrm{~V}$. Figure 9 shows the evolution of voltage across the energystorage capacitors (that is, at the input port of the dc-to-dc converter) in this prototype. As Fig. 9 shows, this voltage is always lower than $500 \mathrm{Vdc}$ and, therefore, two $180 \mu \mathrm{F} / 300$ $\mathrm{V}$ capacitors can be used. Converter efficiency and the main waveforms at $110 \mathrm{Vac}$ and $230 \mathrm{Vac}$ are shown in Fig. 10 and 11, respectively. Finally, harmonic content complies with the IEC 1000-3-2 regulations (Class D) at 230 Vac and with the modified version of these regulations at 110 Vac, as Fig. 12 shows. 


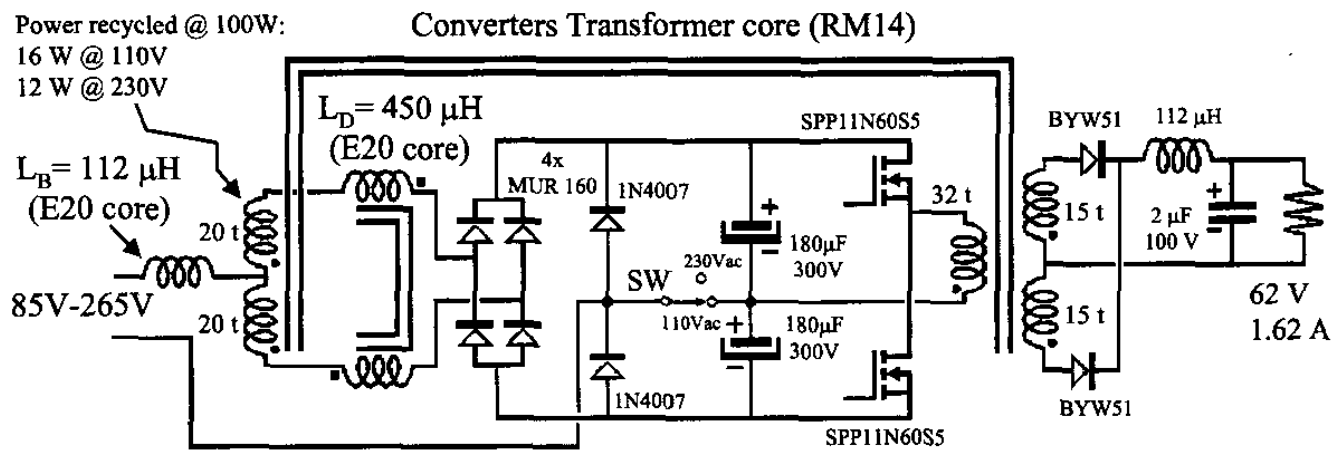

Fig. 8. Converter prototype.

\section{CONCLUSIONS}

A new implementation of a Voltage-Doubler SingleStage Power Factor Corrector (VD-S ${ }^{2} \mathrm{PFC}$ ) has been presented in this digest. This new VD-S ${ }^{2} \mathrm{PFC}$ allows a reduction (by half) of the total voltage drop due to diodes conducting at the same time from the line input to the energy-storage capacitors. Moreover, the size of the additional inductors used to shape the line current is reduced due to the fact that these inductors form part of an additional converter output (which has been designed as HIO), which operates at twice the converter switching frequency, and also to the fact that the HIO duty cycle is higher than in the case of previous HIOs based on a halfwave rectifier. Experimental results show that both inductors can be reasonably built into two E20 cores for a $100 \mathrm{~W}, 62 \mathrm{~V}_{\mathrm{dc}}$ prototype. Finally, the voltage across the series connection of both energy-storage capacitors is lower than $500 \mathrm{~V}$ and the total efficiency of this prototype is $92-90 \%$.

\section{REFERENCES}

[1] F. Tsai, P. Markowski and E. Whitcomb, "Off-line flyback converter with input harmonic current correction", IEEE International Telecommunications Energy Conference, 1996, pp.120-124.

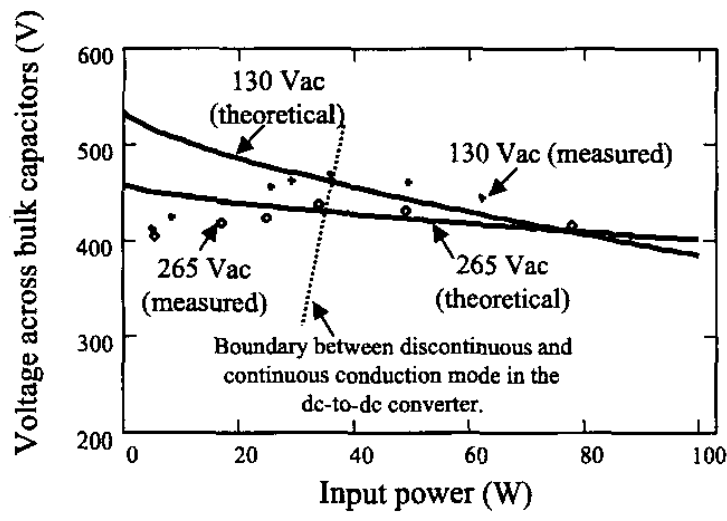

Fig. 9. Theoretical (solid lines) and experimental (dots) values of the voltage across the energy-storage bulk capacitor. Theoretical values have been obtained assuming CCM operation for any input power.
[2] M. Daniele, P. Jain and G. Jóos, "A single stage power factor corrected ac/dc converter ", IEEE International Telecommunications Energy Conference, 1996, pp.256-262.

[3] L. Huber and M. Jovanovic, "Single-stage, single-switch, isolated power supply technique with input-current shaping and fast outputvoltage regulation for universal input-voltage-range applications", IEEE Applied Power Electronics Conference, 1997, pp.272-280.

[4] L. Huber and M. Jovanovic, "Design optimization of single-stage single-switch input-current shapers", IEEE Power Electronics Specialists Conference, 1997, pp. 519-526.

[5] G. Hua, "Consolidated soft-switching ac/dc converters", U.S. patent No 5790389. August 4, 1998.

[6] J. Sebastián, M. M. Hernando, P. Villegas, J. Díaz and A. Fontán, "Input current shaper based on the series connection of a voltage source and a loss-free resistor", IEEE Applied Power Electronics Conference, 1998, pp. 461-467. Also, IEEE Transactions on Industry Applications, Vol. 37, no. 2 March/ April 2001, pp. 583-591.

[7] J. Sebastián, A. Fernández, P. Villegas, M. M. Hernando and J. M. Lopera, "Improved Active Input Current Shaper for converters with symmetrically driven transformer", IEEE Transactions on Industry Applications, Vol. 37, no. 2 March/April 2001, pp. 592-600.

[8] J. Sebastián, A. Femández, P. Villegas, M. Hemando and M. J. Prieto, "New topologies of active input current shapers to allow ac-to-dc converters to comply with the IEC-1000-3-2", IEEE Power Electronics Specialists Conference 2000, pp.565-570.

[9] J. Zhang, M. Jovanovic and F. C. Lee, "Comparison between $\mathrm{ccm}$ single-stage and two-stage boost PFC converters", IEEE Applied Power Electronics Conference 1999, pp. 335-341.

[10] J. Zhang, L. Huber, M. Jovanovic and F. C. Lee, "Single-stage inputcurrent-shaping technique with voltage-doubler-rectifier front-end", IEEE Applied Power Electronics Conference 1999, pp. 112-118.

[11] J. Zhang, F. C. Lee and M. Jovanovic "Design and evaluation of a 450W single-stage power-factor-correction converter with universalline input", IEEE Applied Power Electronics Conference 2001, pp. $357-362$

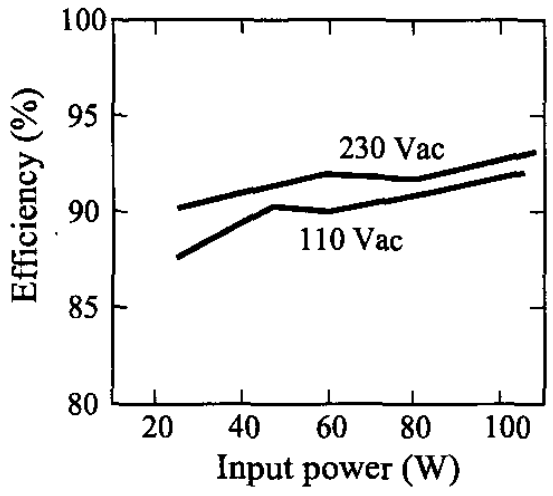

Fig. 10. Prototype efficiency 


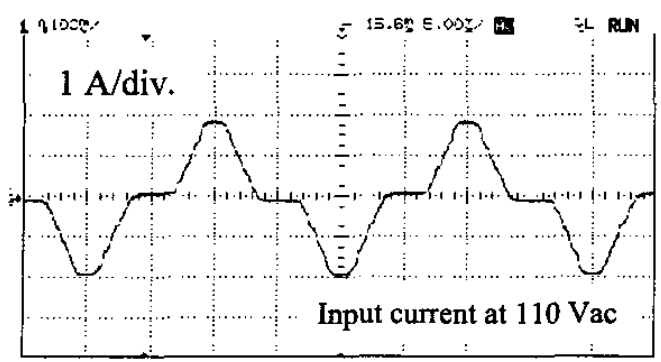

\begin{abstract}
This work has been supported by the Spanish Ministry of Science and Technology under project number
\end{abstract} TIC2001-2595.

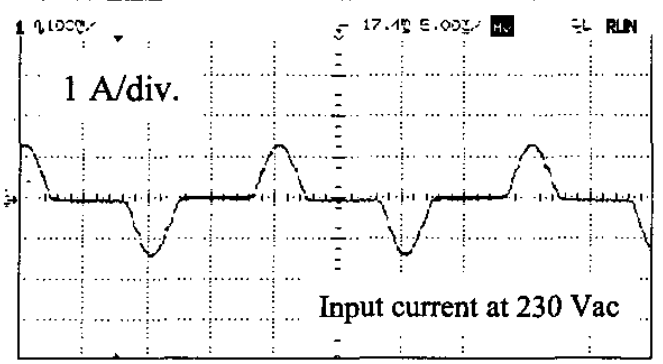

Fig. 11. Measured input current at full load.

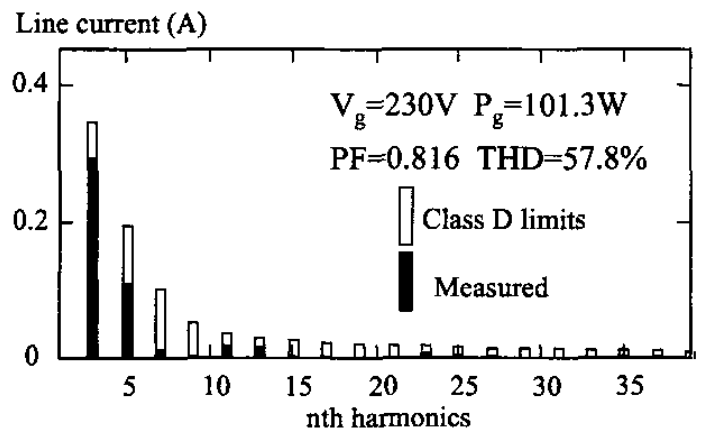

(a)

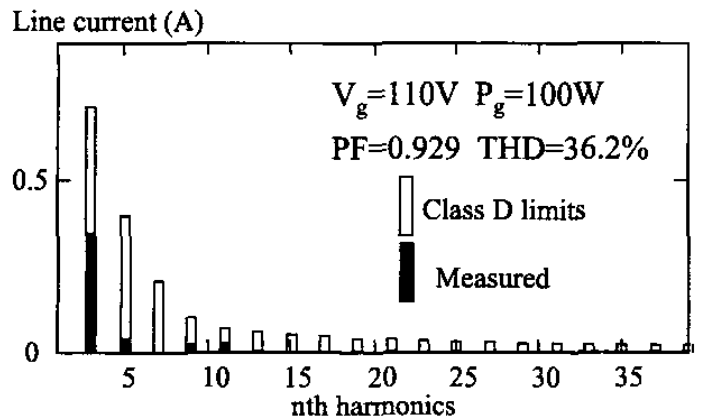

(b)

Fig. 12. a) Harmonic content at 230 Vac compared to the limits specified in the IEC 1000-3-2 regulation in Class D (Class A is less restrictive). b) Harmonic content at 110 Vac compared to the limits specified in the IEC 1000-3-2 regulations in Class D at 230 Vac multiplied by 230/110 $=2.09$.

[12] J. Zhang, F. C. Lee and M. Jovanovic "A novel interleaved discontinuous-current-mode single-stage power-factor-correction technique with universal-line input", IEEE Power Electronics Specialists Conference 2001, pp. 1007-1012.

[13] J. A. Villarejo, J. Sebastián, A. Femández, M. M. Hemando and P. Villegas "Optimazing the design of single-stage power factor Correctors", IEEE Applied Power Electronics Conference 2002, pp. 231-235. 